\title{
Listening to the Literal: Orientations Towards How Nature Communicates 1
}

\author{
Sean Blenkinsop, Simon Fraser University, Canada \\ Email:sblenkin@sfu.ca \\ Laura Piersol, Simon Fraser University, Canada \\ Email: Ipiersol@sfu.ca
}

\section{Abstract}

This paper begins with an assumption that the natural world is literally able to speak. What follows is research around a new place-based, ecological and imaginative public school in Maple Ridge, BC. The school has no building to speak of ${ }^{2}$ as there is an attempt being made, as part of the day-to-day pedagogical practice, to listen to the more-than-human as an active voice and co-teacher thereby moving from human teachers/researchers speaking in, about and for the more-than-human towards speaking with and listening to it. Drawing on our lived experience as researchers, theorists, and ecological educators, this paper proposes to draw on the student voices ${ }^{3}$ at the Environmental School to posit a series of five distinct orientations. Each of these orientations is potentially available to us and each offers a different way to understand, attend to and communicate with the natural world. These orientations have implications, if taken seriously, for educational practice and content. In this paper, we focus on clarifying these orientations and anchor them with examples from interviews done over the course of several school years with three different students. We end the paper by pointing out some of the educational implications that might arise if we are to take these students and, as a result, the proposed orientations seriously. 
A theory of place that is concerned with the quality of human world relationships must first acknowledge that places themselves have something to say. Human beings, in other words, must learn to listen (and otherwise perceive). (Gruenewald 2003, p. 624)

The world and I are of one Mind. - Chief Joseph

He [the tree] often talks to me about my day and feels inspired by what I share. Then he tells me about his day... kids were climbing on him and stepping on his roots which he doesn't like. To him this is an insult. Even when my friends [sitting in the tree] are talking to me, I can hear the tree say 'hey, they are sitting up here, did you ask? - Julianne, seventh grade student, Maple Ridge Environmental School

\section{Introduction}

In his doctoral work with Anishinaabe elders, Beeman (2006) was struck by an insight regarding the lived experiences - more specifically — the explanations of lived experiences of these men who spent most of their lives in deep connection with and immersed in the boreal forests of Northern Ontario. This switch to directly honour the phenomenological offering of the experiencer, particularly pertaining to the way these elders listened to and spoke with the natural world, changed the very fibre of Beeman's graduate work while revolutionizing his understanding of environmental connectedness. Beeman realized that his understanding of their meaning and the space and perspicacity of their insights changed significantly if he stopped interpreting what they said as being metaphorical and understood it as literal.

My first response-before noticing it as a response-in encountering a statement such as Michael Paul's [one of the Elders] was to regard it as metaphor. By this I mean that I supposed Michael Paul could not have been speaking about what actually happened - he had to be consciously choosing symbols that would help me make sense of his words. ... At a certain time ... I began to question my own readiness to make metaphor of the experience of others. Perhaps this occurred when the learning that consists in the uncertainizing of one's ideas, set in. I began, instead, to regard the literal words of the Temi-Augama Anishinaabe elders with whom I associated as usually accurate representations of what they thought, especially of what they thought about how the world worked. (I am leaving aside for the time being that all language can be construed as necessarily metaphoricalthat words by their nature stand for things). (Beeman and Blenkinsop, 2008, p.14)

Every day we are involved in communication with the more-than-human world on some level. We observe the dwindling leaves on the trees on our way to work which tell us winter is coming; a dog runs up to us in the park and we immediately interpret its body language to understand whether or not we need to start running as well. Yet, our commonly held modern and western societal perception of the natural world as a collection of objects 
has made us deaf to the fact that trees, rivers and even rocks could actually be more significant partners in dialogue. Christopher Manes (1995) points out that in western culture to say 'nature speaks to me' strikes most people as "semipsychotic" ( p.18). Why would we listen to something that is supposed to have no voice? We have no problem referring to texts or art as speaking subjects: "That sculpture speaks to me...” or, “The book says....” are common expressions, but to add, "The tree says...” sounds preposterous.

It's easy to dismiss this as 'romantic,' 'crazy,' 'the sacred,' or, as Beeman (2006) points out, to make a metaphor of it. Yet one wonders, if there are enough examples of this 'mania' being spoken, when does it become important to actually stop such dismissive attitudes and, instead, honour these expressions of lived experience? David Abram (1996) points out that for most cultures, including our own in preliterate times, the entire world spoke; the birds, rain, trees and the land are speaking.

I've been trying to write about how the more-than-human world speaks to me and it all comes out as metaphor. The snake sharing lessons about moulting and growth, the sunset showing me the light and dark parts of understanding, but this is not what I intend to say. The snake literally spoke to me. I did not have heat stroke nor was I a five year old when it happened, nor, to the best of my knowledge, have I lost my mind. The snake said 'be still and be quiet'. And I waited and watched as it shed its skin. That's not all it said, it literally told me how to carry myself through the rest of that day; it told me about my limitations and my abilities. It told me about other ways to be in this world, ones that are cold and curving and salt scented. That snake, not a metaphor but a presence that crawls wide and calls wild, literally spoke to me. (Personal journal entry, Piersol, 2011)

Let us be clear, language itself is metaphorical and we cannot escape this; nor, for those of us who speak romance languages, can we ignore the tendency of language to distance us from the natural world. In response, Abrams (1996) and Kleinberg-Levin (2008), for example, have worked to poeticize or re-animate our language such that we stay mindful of 'the things in themselves' while we metaphorize away. Within this paper we, like Beeman, begin from the position of taking the words of our interlocutors at face value, we listen to their literal interpretations of lived experience.

Within our review of the literature, we found varied notions of 'listening' and 'speaking' in relation to the natural world. Some, like Beeman (2006), Carbaugh (1999), Basso (1986) and Styres (2011) explored the concepts in relation to indigenous ways of knowing, with most focusing upon more enigmatic, spiritual and sacred understandings. For example, "Things, people, animals, and places are interconnected in ways that are knowable, and unknowable; spirits exist in things, people, animals, and places. The basic moral imperative: people should be attentive to this.” (Carbaugh, 1999 p. 263) Others, often with obvious phenomenological bents drawing on the work of Merleau-Ponty and Heidegger, such as Cooper (2000), Kleinberg-Levin (2008), and Abrams (1996) suggest that language has its origin in the more-than-human world and as a result suggest a return to or an active remembrance of an infant's pre-linguistic/pre-cultural experience of listening to the world. Kleinberg-Levin(2008) advocates for "a reversible communicative relationship with nature" which allows our return to "a pre-personal experience prior to the child's entrance into the language of its community and prior to the emergence of ego- 
logical consciousness” ( p.61). He goes on to suggest that this pre-personal, pre-linguistic experience of infancy has in fact "already evoked and attuned the human voice" (2008, p.61) in each of us. Still others, Carbaugh and Cerulli (2013), argue that understandings of what it means to listen to place shift depending on personal interpretation and individual context or culturally specific understandings or, with more specificity, argue that 'listening' to the natural world should become a moral imperative within science such that scientists no longer consider themselves as "spectators" but "as participants, learning to listen to the other agents that relate to us" (Cooper 2000, p.1025).

Thus, it seems as though within the literature, listening to the natural world can be associated with the spiritual, the sacred, the enigmatic, and the indigenous or as a way to connect with pre-linguistic states of knowing. However, the literature is extremely limited with regards to non-indigenous peoples and listening to the natural world within public education, nor is there an extended discussion that the more-than-human world is an active, subjective, agential speaker of its own accord. The literature appears to be making the metaphorical leap that Beeman wanted to avoid. Within this paper, we'd like to offer a more literal interpretation; one that builds theoretically out of the many voices appearing across the research including our own. This theoretical discussion acts as an interpretational framework, a home for the children illustrated here but expansive enough to include encounters of the kind Carbaugh (1999) offers with regard to his work with Blackfoot culture.

The 'belief' that the natural world is expressively active is, according to Two Bears, not a fanciful or farcical mysticism, but a Blackfeet kind of "realism". People, animals, rocks, and trees are actually co-present and co-participant with people as embodiments of the spirit(s) in the world. Attending to this "real" world is a key motive for "listening," and renders animals and trees and places generally as spirited speakers to-and thus as potentially hearable by- us all. (p. 259)

Within this article, we have attempted to embody the phenomenological by portraying the students' lived experiences as they literally interpret them in situation and in context, as opposed to interpreting their words in a space removed and devoid of that which helped give their thoughts life. Given Kleinberg-Levin's (2008) work describing the pre-linguistic connection to the natural world, we have found a parallel in this work with children under the age of ten. These students seem ontologically fluid and receptive to the offerings of the natural world. With these students we wish to present what Cooper (2000) describes as the "possibility of direct contact unmediated by language” (p.1021).

This research arises in part from a new public school in Maple Ridge, BC which has a place-based, ecological and imaginative focus and, possibly most importantly, no building to speak of. ${ }^{4}$ There is an attempt being made, as part of the day-to-day pedagogical practice, to listen to the more-than-human as an active voice and co-teacher thereby moving from human teachers/researchers speaking in, about and for the more-than-human towards speaking with and listening to it. If we start with the assumption that the natural world is speaking than we must acknowledge that when we speak at the school, we are actually speaking over other voices, interrupting other conversations. Drawing on our lived experience as researchers, theorists, and ecological educators, this paper proposes to use the Environmental School and the student voices ${ }^{5}$ to posit a series of distinct orientations. 
Each potentially available to us and each offering a different way to understand, attend to and communicate with the natural world. These orientations don't appear to be 'linear' or 'developmental' in nature. Rather, they are identifiable positions on being and knowing in the world that have subsequent consequences for our potential to communicate with and re-orient towards the more-than-human world. This has further implications, if taken seriously, for educational practice and content. Each orientation also has unique ethical implications regarding our interactions on the planet. In this paper, we focus on clarifying these orientations and anchor them with examples from interviews done over the course of several school years with three different students. We end the paper by pointing out some of the educational implications that might arise if we are to take these student voices and, as a result, the proposed orientations seriously.

\section{Orientation \#1: The Accidental Listener: Direct Encounter and Simple Interpretation}

This orientation towards listening to the more-than-human world is the most common one that the modern western world uses. The natural world is not really seen (heard) to be actively communicating at all, however there are folk knowledge and particular encounters that make sense through human interpretation. For example, imagine you are returning home after a long day away and are greeted at the door by your dog, tongue hanging out, mouth open and tail wagging furiously. You draw an understanding of its state of mind then, while you are petting it the tail stops wagging, the dog turns, cocks its head, flexes its ears, appears to listen and then turns and runs barking to the back door. What is being conveyed? What information are you gathering from this scene?

For most of us, this dog episode is fairly easily interpretable. The dog appears to be happy to see us upon our return and then notices something interesting or unusual towards the back of the house that we don't notice. The communication here rests on our abilities to interpret the innate behaviours of the animal; there is limited sense that the dog is actively trying to engage us, more that it is doing what dogs do and that it is up to us to sift through and garner what information we can, likely mediated by our own experiences with dogs, our knowledge of this dog, and a myriad of other things. The information we gather from nature's communication at this level tends to be fairly rudimentary and often hit-or-miss. We glance to the sky, see more clouds than we saw an hour ago and assume weather is about to happen. The specifics - type of cloud, the wind patterns, the time of year, and our geographical position - tend to go under-examined or not understood with respect to the process of anticipating precipitation. We are, in Abram's (2010) terms, fairly unaware of the other as something active or capable of communicating:

But how does my weight feel to those grasses; how do my steps feel to the terrain itself as I walk upon it? As this question rises, I begin to sense the carelessness with which I'm commonly clomping around, greedily amassing sensations. My legs inadvertently slow their pace as the sensitive presence of the land seems to gather beneath my feet, the ground no longer a passive support but now the surface of a living depth; and so my feet abruptly feel themselves being touched being felt by the ground. My feet are like ears listening downward, and a dark rhythm rises up 
into me from this contact- a pulse that slows down and deepens the private beat within my chest. (p.59)

Some have even suggested that this simplistic, careless orientation towards the natural world has been actively adopted through a puerile cultural adolescence (Shepard, 1982) or an intentionally 'dumbing down' in order to justify the destruction we have brought. This implies a kind of cultural deafening to the complexities of the world, so that we come to collectively not know that the world is filled with active, engaging, communicating others. The result, we can destroy at will without feeling the pain or hearing its cries. By denying that the more-than-human communities within nature have the ability to 'speak' to us it makes it much easier to use them instrumentally. The effect is that we destroy "the larynx of the biosphere" (Evernden, 1993, p. 17). It is much easier to pave over a field if you aren't aware of the subtleties of voice that it presents: the nibbled grass telling us a rabbit lives there, the intricate tunnel system indicating there is a healthy population of moles helping to lower the number of insect 'pests' in the neighbouring farmer's field or the wildflowers covered in bees communicating that this is stopping place for the pollinators who supply much of our food. Symbolically cutting the vocal cords of these relations allows us to perceive this same place as an empty field, a wasteland, waiting to be developed solely for our use (Evernden, 1993). By ignoring or suppressing the intricate ranges and astonishing variety of voice within the more-than-human world, we deeply diminish our ability to relate with the 'other'.

In spite of this need to not hear, voices of the natural world are offered to us continually: a house finch sings heartily from a tree-top, a large ' $\mathrm{V}$ ' of honking geese passes overhead, flying south, a maple’s leaves turn red and gold, Orion's belt appears in the sky - all clear signs, carrying readily interpreted messages. However, from this orientation, most of those voices are "backgrounded" (Plumwood, 2002), such that they slide out of our awarenesses, deemed less worthy of our attention than other "more important' culturally foregrounded messages: the clothes we wear, the cars we drive, and the music that speaks to us. We are actually quite adept at doing this kind of separating and ignoring 'white noise' in our lives. In this case, it is the 'green noise' that lost or tuned out. In the instances when those voices are actually recognized, such as the changing of the maple leaves, we hear it as "fall is coming", demonstrating an interpretation so simplistic that it can be seen as childlike by those who are well oriented in the complex ways of the natural world. Leopold (1949) mentions, "no matter how intently one studies the little dramas of the woods and meadows, one can never learn all of the salient facts about any one of them” (p. 35). Yet, often these communications are understood to be linear, leaves turning red $=$ fall, blossoms $=$ spring, dark clouds $=$ rain, house finch singing = ? ('I have no idea but it must be saying something to other birds...'), Orion rising = ? These are de-contextualized bits of information that have, for the most part, been gathered haphazardly from piecemeal experiences and cultural 'knowns' regarding the natural world.

At this orientation, communication with a member of the natural world is direct, the dog barks because it has noticed something, end of story. The sophistication of the communication attributed to these entities is assumed to be simple because they are deemed incapable of 'language' as we know it. Also, at this orientation there is an implicit hierarchy regarding who is able to communicate and the range of any possible communication. A 
rock, for instance, is seen as an inanimate entity that doesn't illicit an easily interpretable or readable reaction as a dog could, thus, the rock is lesser than the dog and, more expansively, assumed to be lacking agency. For environmental theorist Neil Evernden, this hierarchy of communicative ability allows humans working at this orientation to see themselves as 'better' than the non-human other. For Evernden this inability to hear the other, separates us from any connection to or responsibility for its well-being thereby allowing us to destroy it with a clear conscience. "Deafness is a requirement, for any hint of subjectivity emanating from the world would be evidence of relatedness." (Evernden, 1993, p.99). If Wade Davis is to be believed, this invisibility of our relatedness to or the active subjectivity of the members of the non-human has led to the loss of a myriad of human languages which assumed inter-species communication. These linguistic losses have in turn led of some serious social and environmental consequences for humanity. Davis (2003) suggests that the loss of languages "reduces the entire range of the human imagination to a narrower modality of thought" and as a result limits our ability to respond to the changing environmental reality while also narrowing the range of our own possibilities as humans. What then might this mean for our range of imagination and human possibility if we perpetuate the silencing of innumerable ecologies of wild 'language'? If the loss of one language is like clear-cutting "an old growth forest of the mind" (Davis, 2003), then our deaf approach to the tangled stories of a growing sapling or the reposing rock that still belts out the verbs of ancient glaciers is akin to a mass extinction of our potential selves.

\section{Orientation \#2: The Immersed Practitioner: Reading Signs and Understanding Symptoms}

Although we are suggesting that these orientations are not 'levels' and that they are not indicative of a linear developmental process, this one does more obviously follow on from or grow out of the first. For this orientation, the image is of an organic apple farmer who has twenty-five years of experience on this land and with these trees. As a result of time spent in place with these particular plants, this farmer has a deep knowledge of and a feel for the nuance and complexity of orchard life. This is a person who can both read the signs, the externally diagnosable "facts" of a situation and understanding the symptoms, hear the messages of the plants. Beyond just noticing the needs and realities of water, shade, food, soil friability they recognize brown leaf curl before it takes hold and know how to respond before it gets carried away. They have a sense of how the crop will yield, know when the fruit is being set, and wake in the night to the changing rustle of the leaves as the wind rises and threatens to blow away that same newly set fruit. Or in the words of Aldo Leopold (1949):

There is much small talk and neighbourhood gossip among pines. By paying heed to this chatter, I learn what has transpired during the week when I am absent in town. Thus, in March, when the deer frequently browse white pines, the height of the browsings tells me how hungry they are. A deer full of corn is too lazy to nip branches more than four feet above the ground; a really hungry deer rises on his hind legs and nips as high as eight feet. Thus, I lean the gastronomic status of the 
deer without seeing them and I learn, without visiting his field, whether my neighbour has hauled in his cornshocks. (p.89)

What distinguishes this orientation from the previous one is that this is a much deeper form of communication. There is a relationship implicit in this orientation that has been built over time, through close study, multiple iterations of a parallel experience and a form of co-reliance (the orchard and the farmer need each other) that has the potential to support mutual respect. In this example, the farmer understands and anticipates the others' needs, hearing the myriad, tiny messages and then responding in such a way that the trees and the land know they have been heard and in response, if Pollan (2002) is to be believed, the trees grow appealing fruit.

\section{Eco-boy:}

'Eco-boy', a fifth grade student at the Environmental School can offer some further lessons around this orientation; join us here on a walk in the woods:

We walk toward the fort village and Eco-boy stops at a muddy patch to look at the tracks.

“Looks like dog,” he says. I agree and we look for claw marks. Satisfied with our identification, we keep walking.

He is walking in front of me and again, I'm surprised when he goes off trail away from the fort village. He detours to take a look at the river. "That would be good cover for a fish," he says, pointing to the overhanging tree branches. "There's a dead fish below; you can see it there?” he asks.

“Oh neat," I say, looking to see the body caught in a whirlpool created by a mossy $\log$.

Eco-boy moves closer to take a picture, "Whoa, there is a whole bunch washed up over here!" he calls me over.

I peer down to see about 25 dead fish. "Wow!" It's that time of year after the salmon spawn when the fish begin to die off.

As we are leaving, Eco-boy points a large hole in a log below our feet. "Maybe that's a home for a marten," he decides.

As we enter the fort village he stops and looks in another hole at the base of a tree. This surprises me because he's walked this route so many times. Yet, he still stops to look closely at things as he is walking. He reminds me of his fort from last year and we decide to go check on it. We have to cross a long mossy log about two feet off the ground. Eco-boy is sure-footed and walks slowly in front of me because it has been raining all day and it's slippery. I follow behind him.

"I haven’t been back here in a while," he says. "I remember the water gets so high here so you have to build the floor high. There's the bird's nest.” He points out a mossy ball hanging off a tree branch.

"I think it's abandoned now," he says peering up at it. He takes a photo of it.

"If I had my waders on I'd go down in there." He looks at the pool of water where his old fort used to be. I laugh and say, "Be careful," as I watch him cross a slippery muddy slope.

“There's probably frogs in here now,” he says. 
We look into the pool, checking for that splash of green and listening quietly to see if we hear any movement in the water. As we wait, I realize that instead of simply showing me his fort, Eco-boy has been stopping along the way to show me a community of living creatures that also share this spot and call it home.

The tracks in the mud, those fish in the river beside the village, the bears that he has seen pass through, those holes at the base of the trees, that mushroom growing on the fort, the bird's nest, the frog pond; he has taken the time to pause and attend to all of these things. I normally walk quickly on the trail all the way here and he asks me to divert off of it. I normally only see the human impact on the area in the fort village and he asks me to crouch down and look at the small mushroom I would've easily missed. I thought we were going on a walk to hear about his fort when really Eco-boy has been teaching me what Hartman (1964) calls "halted travelling" ( p.7), pausing to find the wonders under foot and above the head which everyone else passes blindly by. He's busying soaking up the signs and clues that surround him. I can't help but contrast him with Raven, a female fourth grade student at the school, who rarely seems to be observing and engaging in the natural world in this same manner. It's clear that she occupies a much different orientation.

At this orientation, the conversation is extensive and involves careful listening, For the most part, the interpretation still remains solely in the hands of the human. Regarding the interpretation of the message, although $\mathrm{x}=\mathrm{y}$ is now too simple an equation and now has become $\mathrm{x}+\mathrm{z}$ (under the conditions $\mathrm{s}$ and $\mathrm{t}$ ) can lead to $\mathrm{y}$ (unless of course $\mathrm{r}$ or $\mathrm{w}$ happen), there is still a sense of independence from the orchard or tree one is considering. The receiver must interpret the message delivered from a discrete communicator. It is this interpretability coupled with ethos that has educational implications as we begin to consider the next two orientations.

Given our example of an organic apple farmer, there are already implications that can be drawn with regard not only to that farmer's orientation but also to their learned and ethical stance towards the orchard itself. For example, we can contrast the organic farmer to another long-time apple farmer. Both have spent a lot of time caring for an orchard, and yet the range responses available to the recognition of leaf curl and the presence of mites is different. The direct and immediate application of a chemical insecticide is part of the available repertoire of the non-organic grower. This farmer understands how to push trees through fertilizer treatments and use climate manipulation to produce abundant crops. They also recognize when a tree needs to be replaced as a result of exhaustion. This person is situated in what ostensibly is orientation \#2 and yet, they are not enacting the kind of responses that might be more ethically indicative of a farmer who operates from the stance of hearing the world around them. They continue to be situated in a particular kind of anthropocentrism that gets in the way of the kind of listening described with the organic farmer example.

Val Plumwood (2002) along with Andrew Light and Eric Katz (1996) have discussed a form of enlightened or inconclusive/empathic anthropocentrism which recognizes that, as humans, we inevitably understand the rest of the world through the tools we are provided (e.g. culture, language, binocular eyes in the front of our heads, etc.). Yet, we can choose how to hear and encounter, as we can with other humans. Revisiting our two farmers, we can see that one responds to leaf mite through ample use of insecticide and the other through active adjustments of the surrounding plant guilds in order to provide appropriate environments for leaf mite predators. A difference appears as to how each farmer ethically 
understands the 'other' that is tree, insect, orchard, eco-system, and food. It is this kind of difference in ethos that Naess (1986) sketched in when he separated deep from shallow ecologists. For the deep ecologist connection to the complexity, diversity, and implicit rights of the natural world are assumed and enacted whereas for the shallow ecologist there is a veneer of green being added to the way things currently are. The move into a deeper way of knowing involves an initial shift away from the implicit norms of modern western culture that presuppose that the non-human world is of lesser worth, available for active manipulation, and not capable of communicating except in the form of rudimentary signs and symbols. The organic farmer in our example has, at the very least, begun to deepen their relationship with the non-human. They have begun to release their role as steward, technicist, overseer, or controller and are leaning towards friend/student. Such an ethos allows for a turning toward or an opening into the next orientation as there is a sense that the non-human has a kind of activeness, even agency, which is deserving of being heard.

This discussion has important ramifications for the educator. It appears, assuming that the organic farmer mentioned above initially approached the world from orientation \#1, that there is an educational conversation here with regard to how that move occurred. Lacking enough space to give this conversation its due, we will at least point to Heidegger's notions of presence-at-hand and ready-to-hand. For this very experienced farmer, the apple trees, the leaves, the flowers, the fruit, the environmental context, the particular organic responses to ill health, etc. are a kind of ready-to-hand. However, they are not, assuming modern western cultural context, the normal version thereof. That is the trees' and leaves' organic responses to ill health at not ready-to-hand in the same way for the person of orientation \#1 as for this farmer. Educationally, then, we suggest that if the project is related to changing orientations from 1 to 2 there is a method that might occur through using an active presencing-at-hand process. In this project, the learner comes to step back from the assumed 'ready-to-hand' positions that they are already inculcated with, thus making them 'present-at-hand' and then actually choose, from this distance, the new 'ready-to-hand'. This active process plus a very conscious process of following through in one's lived practice (ie. acting as if one believes and follows the new chosen ready-tohand) then allows, over time, for the old ready-to-hand, along with its implicit cultural and orientational assumptions, to be replaced with the new version. It is important to note that, although this might point towards educational possibilities for other orientational movement, we are less convinced as the orientations become more obviously distant from one another.

\section{Orientation \#3: The Complex Knower}

At this orientation we begin with a climber. She has a significant amount of backcountry and climbing experience. Yesterday she made her way into a backcountry hut so that she could get an early rise in the morning, work through the approach and be on that looming multi-pitch cliff as soon as possible. The approach involves making her way through a very rugged boulder field. She and her partner scouted the route the day before and are feeling that mix of excitement and trepidation so common to climbers on the eve of a push day. As she wends her way through the boulder field in the early morning light she makes seemingly unconscious decisions about where to put her feet, her hands, her weight and 
she, as if by magic, avoids those boulders, no matter the size, that are loose, dangerous and likely to move. A steep boulder field is a delicately balanced and highly unstable place, the application of pressure in the wrong spot can send appliance-sized rocks (not to mention climbers) crashing towards the valley below. Yet, her navigation is spontaneous, particular, and fluid; she is of this place. Boulders and climber in dialogue, safe passage offered and found, through a place where the outsider would struggle and fail to understand the nuance of the interaction itself.

There appears to be a kind of intuition in action here and yet it is more than that which is colloquially understood as 'intuition'. The climber, in communication with the place, actually knows where to lean, knows the balance points of these giant stones and knows the next step. She is certainly an expert who has an experience and knowledge that parallels the organic farmer of the previous orientation but she also knows differently. She has to be able to respond quickly to the specifics of this boulder field, a shifting and moving environment, and she can't really tell you how she knows where and where not to step; she just does. We want to suggest that this is pointing towards an orientation that requires a shift in how we know. We are also trying to sketch in a space between a complete ontological shift, which we shall explore in the next orientation, and one that has made a move out of a modern western cultural construct but is not completely foreign either. The climber is not one with the rocks, nor has she had her sense of herself expanded such that the rocks are included within 'she' but rather, she is involved in a more expansive conversation with nature that allows her access to information and knowing that would not be part of the previous orientation. Given this, let us take a glimpse at a student that may offer further insight into this orientation.

Bambi:

Most of the students are moving quickly along the trail. I notice Bambi, a first grade student, at the back of the line as usual. She is refusing to move while other kids scramble to get by her. The teachers encourage her to keep walking but she is resolute. I see that she is scooping something off the ground. "Look!" she thrusts a slug in my face, "I want to move him off the trail so that no one will step on him." She lays it down on a bed of moss away from the path. We walk a bit further and she yells at a boy in front of her who is standing on a decaying log. "Get off of that!" she complains. "Why should I?” he demands. I ask her why it's making her so upset. "It's alive.," she tells me. I argue back that is was an old tree that is now dead. The boy hops off and she reaches over and points at the green moss that was trampled under his feet.

As we make our way through the forest, I feel like she is acutely aware of her footprint regarding certain things. In contrast to the other students this means she moves through the place differently, slower and watchful, but also I think this means that she has different knowledge of it, varied and full of life. As she grows older, she seems to intuitively know it as a 'home' for other creatures and her possible impact on that home changes the way she walks in it. Bambi picks up the slug knowing that it will get hurt if we step on it. But, she does not necessarily feel that hurt herself. The difference between this and the next orientation might be that instead of picking up and moving the slug, we might move ourselves, thereby leaving the slug to its journey.

There is a connection or relationship within this orientation that wasn't in the last. There is a sense of not just being able to read the signs and symbols but also an 
implicatedness or embeddedness that is appearing in regards to how you are related to those signs, symbols, and signifiers. There is also an awareness of how the information and knowing are conveyed between and amongst the players (climber, boulders, larger slope or child, path, living creatures). The climber is not carelessly moving through a field of inert rocks rather, with each step she is listening to and aware of the effect she will have on the slope and the impact that the shifting field could have on her. The eco-intuition perhaps dormant but apparent in the other levels, now begins to emerge and you learn to trust it. If you are the apple farmer, you have a sense of how much to prune, you feel your way into the timing, and you have conviction in regards to this knowledge, cutting with confidence or stepping around boulders and up the slope in fluid motion. This confidence comes from the depth of knowledge that has been cultivated in the other orientations, but also because of the back and forth heightened awareness/listening that happens at this stage. You act/speak and wait to hear/feel the answer, this happens at the 'signs and symbols' level but in a rudimentary way, you are still learning to interpret the answers there. At this stage, the subtle changes are magnified/amplified; you zoom into the details which you didn't quite see before which can give you an answer on how/where to cut/move/speak next and you know it is not just you involved in this. Subsequently, each step is taken seriously, each pruned branch a delicate and deliberate decision. One begins to act with increased carefulness and precaution.

\section{Orientation \#4: The Literal Being in Place}

This orientation returns us to the very beginning of this paper where we encountered Aboriginal Elder Michael Paul and the crisis that his way of being in the world caused for Beeman's doctoral work. Within this orientation one's way of being is different; this is not the ontology of the modern western world but another. Instead of feeling separated from the natural world, one is part of it. From a western perspective what appears to be happening is an extension of self, one is not bounded by skin. It is again important to note that this is not a developmental process. Michael Paul did not begin life ontologically defined by his skin and then find ways to expand outwards. His is a different ontological orientation but one that, we will suggest in the next orientation is possibly available to us all. The key point to note for this discussion is that as a result of this ontologically different orientation, the more-than-human world speaks to you on a literal level, in its own languages and ways. Listen to Michael Paul ...

you wake up

and you have no game plan

and you just go out

maybe you want to paddle

down the lake today

or go up the river

go down the river 
but no matter how you feel

it's you

this land is telling you

what to do (Beeman, 2006)

And then listen to Beeman's response, where we can see one ontological position trying to comprehend another:

I understand Michael Paul to perceive himself, his surroundings, the place he calls home, to be part of a very complex identity that is composed of, as far as I know, at least two aspects of the same thing, which to me would usually appear to be distinct. These are what we would conventionally see as the human body as it is delineated from the world outside it through the large organ of the skin, and the world that is sometimes immediately and sometimes more distantly responsible for that body's survival. (Beeman and Blenkinsop, 2008, p. 2)

This struggle to make sense of what appears to be a different understanding of self within the world recalls Gregory Bateson's (1972) discussion of a man trying to navigate inside a dark cave with a cane. In this complete darkness, the man touches the cave walls with his cane and wonders where his hand, and then, by extension, where his 'self' starts and finishes? Is it where he holds the stick? Or is it where the tip of the stick touches the walls and 'tells' where and how he is? Where does the man begin and the cane end? The boundaries of 'self' and subsequently, who speaks or is spoken to, and what is understood as 'speech' have changed. The tip of the cane is communicating, as is the hand, the challenge is where one draws the outer edge of selfhood.

Raven:

Raven, the fourth grade student already mentioned, is asked what it is like to listen to the natural world after she mentions that she feels like she can talk to plants.

Researcher: "So do you hear the plant?"

Raven: "Yeah, but you have to hear it through your heart."

Researcher: "I was going to ask where you hear it... do you hear it in your heart?"

Raven: "Little words curl into your mind. You have to know that you're not thinking."

Another day the researcher asks her again what the process of listening to the natural world is like for her ...

Raven: "This sounds funny, you're focused on something but you're not actually thinking about it. If you're thinking than you're not really listening. See I can't do it now when I'm talking."

Researcher: "Do you feel like you have 'conversations' with the natural world?"

Raven: 'It's not exactly like that, it's not 'speaking' it's more like energy or signals. You don't hear it out loud. It's something that your mind and only your mind can understand because nature is that open to any language. So if you were just thinking, not even in your language, just showing pictures, it would still work.”

Researcher: "The conversation you mean?"

Raven: "Yes, it doesn't have to be 'speaking'”. 

that?”

Researcher: “So you mentioned 'energies' and 'signals' what did you mean by

Raven: "Well see you speak your way, they speak different ways, like thousands of different ways. Billions. It's like the birds with those signals, like when you see a bird flapping up in the sky and a flock of birds how they all move at the same time, it's because they tell each other like through mental speaking.”

In this extraordinary discussion, we hear Raven trying to find ways to explain how she experiences the world. It is apparent that she has a sense of how different what she is describing might be and also, how aware she is that there are things, like thinking and speaking, that can get in the way of hearing the world speak in its billions of ways. We can hear the ripples of Bateson mentioned above but as encountered in the living spirit of a grade-four child. This process of making sense of her own experiences for others is deeply challenging for Raven. She must translate something into a linguistic, cultural, and ontological context that which has no anchor for what she is trying to say. In fact, as mentioned previously, Raven understands that what she is experiencing and trying to speak can be seen as downright 'crazy'. And yet, she seems unwilling to choose to not hear, not know and not be that which she is and does, actively seeking out quiet and separate time during the school day. She appears to be aware that the natural world is communicating in a different but a direct way, when the words 'curl' into her heart and mind there isn't a need for translation, she tells us that she understands it immediately. In fact, Raven points out that it can occur in the absence of human 'language' as we know it. The fourth orientation is one of literally being in place where body, awareness, self, other, and being are different from those of orientation number one. For educators, this raises a myriad of questions, challenges, and ethical conundrums. In a world where there is growing diversity in our classrooms, in spite of real attempts to ontologically homogenize all humans, how does a teacher respond when students come with completely different orientations? Is it ethical to force any particular orientation upon one's students? And, given the environmental crisis and the seemingly deepening alienation from self and others, how might we educate towards orientations that more ecologically relational and socially just?

For Raven, the listening process is immersive and somatic. "It comes from here [and she points out to the forest in one direction and then brings that hand back into the centre of her chest], and then here [and she points in another direction and brings that hand in] and then here... here... here... and here [she moves her hands in a flurry].” As one of her teacher's describes it, "She seems connected to hundreds of things all at once." Raven's descriptions of how she lives in and experiences the world show a deep blurring of the lines between her 'self' and the 'other', pointing in the direction we think this orientation suggests. In describing her art Raven mentions, "When I am drawing the river it makes me feel watery and thirsty. If there is a something missing on the drawing, I get a little feeling (tilts her head) like I've got to do that (add something). I feel it in my body if something is missing and then I add it. When I draw a tree I feel squiggly. I feel like a tree, like if I need more branches I don't feel so good and then I just put some branches on.” It is interesting to note that this goes unnoticed by most others at the school. A member of staff does comment that "Sometimes I feel like Raven actually feels fall”. "The season?" a researcher asks. "Ya, the falling of the leaves, the coming of cold, the coming of weather as she stands there and thinks." The staff member describes it as her "soaking” it all in. 
This clear sense of extended self, coupled with the challenge to describe it in an adequate manner, might be key signs of this orientation. There also appears, in the case of Raven at least, a form of ethics born of this empathy - a feeling of and for the world that is oneself. One day, Raven says she has to leave the forest as she watches other students uprooting moss and ruining stumps. "It makes me feel sick to my stomach," she says. At this orientation because the self is intertwined with the other there seems to be a more visceral embodied reaction when the other is impacted. The loss of a limb of a tree literally feels like the loss of one's own arm. Another student shares, "When I hear moss being stripped off a tree, it feels like bones are being crushed." This has the potential for a profoundly different way of being and knowing in the world, one that treads with the utmost care, sensing webs of relation, knowing that one impact can be far reaching.

\section{Orientation \#5: Pre-ontology and the Possibility for the Ontologically Fluid}

In the previous orientation we suggested that Michael Paul was not born into an ontology where self was defined by the edge of one's skin and then expanded out into his different adult ontology. He was in fact part of a community where self as more expansive was the norm, yet Raven, despite her similarities to Michael Paul, was born into an ontology where self does end with skin and where one does not communicate with nature in ways she is clearly describing. So, in response to this conundrum, we offer a final orientation, or possibly more appropriately the first or even pre-orientation. One that is so fluid that it allows any individual human the possibility of being in the world in potentially an infinite number of ways.

Wade Davis (2009) in his Massey Lectures entitled “The Wayfarers” makes the claim that there is a global human resource library of possibility available to all humans, which is made most manifest in the incredible diversity of cultures that exist. As we destroy these cultures, their languages, and by extension their ontologies, we are in fact limiting our own possibilities as humans. And yet, hope springs, for this suggests that there is at least some level of flexibility regarding who each and every one of us might become. If one were raised from infancy with the Polynesian seafarers might we sing islands into existence (as Davis suggests the wayfarers do)? Or if it was in Northern Ontario, the land of Michael Paul where that rearing happened, perhaps we would be surprised that understandings he expressed could be so earth shattering to a doctoral candidate from the south? Or, might we still, if we stop thinking and talking, catch a glimmer of the communications and energies that seem so constantly a part of Raven's life? For the educator, this opening of a possibility offers an extraordinary set of challenges to consider, questions to ponder, and responsibilities to weigh.

In this orientation, we meet the infant who doesn't distinguish themselves from their mother, or who responds by crying when another cries, or who lies on her back staring up into the branches of a tree for hours. These young children are incredibly subtle feelers and responders; they seem to soak up everything that is around them, such that their self is porous and wide open. As Kleinberg-Levin (2008) describes, 
the infant's body of breath is a body without airtight defenses, without fixated boundaries. Confronted by the child's experience, can we say where our breath ends and where the winds begin? Is there any point in the atmosphere that can really be a matter of indifference to our breathing? Breathing is our most fundamental openness, our most fundamental experience of non-duality. (p.79)

This fluid sense of being is similar to the last orientation in that it's hard to tell where the boundaries of where the 'I' resides. Yet, it is different in that it is, in fact, a kind of preontology, a flexible position from whence all ontological possibilities might arise. This orientation is seeking cues from their environment as to where that line should be drawn. They are in the process of darkening it into solidity from the very first moments of life.

Bambi, redux:

It is interesting to note that in the case of Bambi, the grade one student previously discussed, we might have found an example of this as yet undifferentiated ontological orientation. On one hand she seems so incredibly immersed in the natural world that her mother comments it's hard to tell where Bambi ends and 'mud' or 'tiger' begins, on the other, we witness her literally loving the world to death. On a daily basis, she can be found squeezing a worm too hard in her affection for it or removing creatures from their homes and habitats so as not to be parted from them and because she feels like she can 'protect them best'.

Coming into the world, we don't know where our edges are, we haven't had "communication" or even "ourselves" defined for us by our cultures and we also don't have a sophisticated ability to understand what is being communicated to us. Thus, it appears that Bambi entered the school seamlessly connected with the natural world without having various tools that might help her to make sense of it. This stands in stark contrast to the tools we saw Raven actively employing in the previous orientation. Bambi, lacking the necessary tools, does not yet understand the natural world as 'communicator', selfinternal to skin is understood as all there is and thus, there appears to be no realization that there could be a feeling/sensing 'other' outside of herself. So, if she didn't feel pain then neither did the worm she was 'hugging'/squeezing, nor did the butterfly trapped in her backpack. She appears to have little awareness that the other has agency or the ability to engage with her and yet, she is aware of the smallest details in the natural world that others would quickly pass by.

It is worth noting Bambi has recently been 'taught' the notion of an 'other' that has the capacity to feel things that she cannot know. We now see her sorting out this realization by moving the slug on the trail in the earlier orientation. Previous to this she would've picked it up and "carried it for over an hour with slime oozing out of her little hands," as her mum describes. It is at this early pre-ontological orientation where the educator/parent might play a critical role if we are to shift towards a more immersed ontology or allow for this more flexible human possibility that Davis is pointing towards.

The last orientation, which is admittedly a pre-orientation, or a state of immersion and un-differentiation with the world, harkens back to the pre-thetic, pre-consciousness experiencing that has been described by various phenomenologists from Husserl to Kleinberg-Levin. For educators, the example of 'Bambi' works as illustration, but raises questions: how and when to best involve more-than-human teachers? How early the 
sedimentation of orientation might begin? What the content and practice of pre-orientation education might be if we are to allow students maximal ontological fluidity? And what is gained and lost when the sense of the 'other' becomes 'literally' and 'metaphorically' thematized?

\section{Conclusion}

Currently, we mainly occupy the 'direct encounter and interpretation' orientation regarding the more-than-human world within the conventional school system. It's hard to build the nuanced skills of reading signs and symbols in the way that the apple farmer can if students don't have ample time and experience within the natural world. And, it's downright implausible to feel an expanded sense of self if we inculcate students in the dominant norms of modern western culture, which deem nature as something 'far and away' or as a resource for human use.

We believe that an ecologically conscious ethos requires serious consideration into the orientations and examples of lived experience offered here. As mentioned, if we take seriously the perception that the more-than-human is capable of communication on a literal level and is thus, capable of being a 'co-educator', this demands a radically different approach to education as we currently know it. Anthony Weston (2005) describes,

A visiting alien anthropologist would surely be amazed by our practice of teaching young people about their belonging to the world in rooms that are sealed off as enthusiastically as possible from anything but themselves, even to the extent to keeping the blinds closed and windows shut if we are so lucky as to have windows at all. (p.9)

Thus, an absolute requirement is venturing beyond the classroom and into the morethan-human community to learn. As educators, we need to carefully attend to the preontological orientation previously described, such that the boundaries and understanding of communication are not limited to our species alone. This means, within pedagogy and curriculum, we begin to work with the natural world as a co-teacher rather than solely asserting our meaning upon it. As Annie Dillard (1974) describes,

Two billion bacteria and many millions of protozoa and algae in a mere teaspoonful of soil... I might as well include these creatures in this moment as best I can. My ignoring them won't strip them of their reality, and admitting them, one by one, into my consciousness might heighten mine....” (p. 96)

This means releasing our grip on the world as stewards or controllers and, instead, re-orienting ourselves in our positions as educators to become humble listeners and learners when it comes to all things winding, whirling and wild. As educators/parents, we have an obligation to stop echoing the dominant western cultural norms that discount the experiences of students such as Raven. If not, we perpetuate a dangerous level of cultural deafness, effectively ignoring 'billions' of languages, which could be informing the human potential of our students and ourselves. We must instead work to see what the phenomenological offering of 'nature as communicator' can teach us. By widening the 
scope and depth of our capacity to communicate with the natural world we have the opportunity to explore new, diverse ways of knowing and being that have long been silenced or ignored within traditional educational practice (Evernden, 1993). We also have the opportunity to actively work together with the more-than-human world to overcome generations of ecological damage, to find ways to reconcile ourselves to those who share the planet with us, and to, over time build the deep and meaningful relationships that are pivotal to surviving this human induced ecological crisis.

\footnotetext{
${ }^{1}$ This research was supported by a grant from the Social Sciences and Humanities Research Council of Canada.

${ }^{2}$ For more information on the school go to http://es.sd42.ca/

3 The reader steeped in Husserlian phenomenology will likely notice the parallel between this orientation and the natural attitude which is a fair comparison with several caveats. The first relates to the culturally specific character of Husserl's natural attitude. As will be seen with the example of Anishnabee Elder Michael Paul in orientation \#4 to speak of his natural attitude as being orientation \#1 is quite absurd. Thus, the second caveat with regard to assuming that orientation \#1 is the natural attitude is that we would argue, if given more space, each orientation is in fact a natural attitude. Described here are a series of different natural attitudes. The educational challenge then, should we choose to accept it, involves supporting learners into developing a new natural attitude.

${ }^{4}$ Students are referred to through pseudonyms of their own choosing

${ }^{5}$ Although the place is guiding him in inquiry, Eco-boy in other interviews is confused about whether it has the ability to 'communicate' with him. He seems adept at reading the land and listening to its' signs but in his opinion, the interpretation of them is still solely up to him.
}

\section{References}

Abram, D. (1996). The spell of the sensuous: Perception and language in a more- thanhuman world. Toronto: Vintage Books.

Abram, D. (2010). Becoming animal: an earthly cosmology. New York, NY: Pantheon Books.

Basso, K.H. (1986). Stalking with stories: names, places and moral narratives among the western Apache. In D. Halpern (Ed.), On nature (pp. 95-116). San Francisco, CA: North Point Press.

Bateson, G. (1972). Steps to an ecology of mind. Chicago, IL: University of Chicago Press.

Beeman, C. (2006). Another way of knowing and being. Doctoral dissertation. Queen's University.

Beeman, C. \& Blenkinsop, S. (2008). Dwelling telling: Literalness and Ontology. Paideusis, 17(1): 13-24.

Carbaugh, D. (1999). “Just listen”: "Listening and landscape among the Blackfeet. Western Journal of Communication, 63(3): 250-270. 
Carbaugh, D. and Cerulli, T. (2013). Cultural discourses of dwelling: Investigating environmental communication as a place-based practice. Environmental Communication, 7(1): 4-23.

Cooper, N. (2000). Speaking and listening to nature: Ethics within ecology. Biodiversity and Conservation, 9: 1009-1027.

Davis, W. (2003). On endangered cultures. TED Talks. Monterey, CA. Accessed April 15 $5^{\text {th }}, 2011$ from http://www.ted.com/talks/wade_davis_on_endangered_cultures.html

Davis, W. (2009). The wayfinders: Why ancient wisdom matters in the modern world. Toronto, ON: House of Anansi Press Inc.

Dillard, A. (1974). Pilgrim at Tinker Creek. Toronto, ON: Bantam Books Inc.

Evernden., N. (1993). The natural alien: Humankind and environment, ( $\left.2^{\text {nd }} \mathrm{ed}.\right)$. Toronto, ON: University of Toronto Press.

Grunewald, D. (2003). Foundations of place: A multidisciplinary framework for placeconscious education. American Educational Research Journal, 619-654.

Hartman, G. (1964). Wordsworth’s poetry, 1787-1814. New Haven, CT: Yale University Press.

Kleinberg-Levin, D. (2008). Before the voice of reason: Echoes of responsibility in Merleau-Ponty's ecology and Levinas's ethics. Ithaca, NY: State University of New York Press.

Light, A. \& Katz, E. (1996). Environmental pragmatism. London: Routledge.

Leopold, A. (1949). A Sand County almanac. Toronto: Random House Inc, 1966.

Manes, C. (1995). Christopher Manes. In D. Jensen (Ed.) Listening to the land: conversations about nature, culture and eros. San Francisco, CA: Sierra Club Books.

Naess, A. (1986). The basics of deep ecology. Trumpeter, 21 (1), 2005, 61-71.

Pollan, M. (2002). The botany of desire: A plant's eye view of the world. NY: Random House Inc.

Plumwood, V. (2002). Environmental culture: The ecological crisis of reason. NY: Routledge. 


\section{Blenkinsop \& Piersol}

Shepard, P. (1982). Nature and madness. San Francisco: Sierra Club Books.

Styres, S. (2011). Land as first teacher: A philosophical journeying. Reflective Practice: International and Multidisciplinary Perspectives, 12(6): 717-731.

Weston, A. (2005). What if teaching went wild? Abridged version. Green Teacher, 76:812. 